\title{
Palo Alto Medical Foundation, Research Institute
}

\author{
Marcus A. Krupp, M.D., Director, Emeritus \\ Allen D. Cooper, M.D., Director
}

In 1949, Dr. Russell V. Lee persuaded several friends to join him in establishing the Palo Alto Medical Research Foundation to serve as a laboratory for practicing physicians in the community. Because Stanford Medical School was in San Francisco, the new Research Foundation was to fill the need for medical research in Palo Alto. Activity in the new entity languished, forcing the decision to get a full-time director. Dr. Marcus Krupp accepted the challenge and came to Palo Alto in April 1950 to start a research institution from scratch with a total fund of $\$ 90,000$.

An old house (Fig. 1) was made available by the Palo Alto Medical Clinic for a rent of $\$ 1$ per year. The house was remodeled to contain laboratories in the three former bedrooms and kitchen, a library in the living room, and a business office in a glassed-in porch. The initial staff included Barend H. Hofstee, Ph.D., Marcus A. Krupp, M.D., two technicians, and a part-time secretary-bookkeeper. Dr. Hofstee started work on enzyme dynamics, especially on lipid substrates; Dr. Krupp studied water and electrolyte metabolism in human subjects.

With the premise that good investigators should be free to follow their own research trails, emphasis was placed on recruiting talented and creative researchers, which led to the addition of two principal investigators-one to pursue carcinogenesis and the other, immunology and allergy. They remained, however, for only a brief time at the Research Foundation.

During the autumn of 1956, the Research Foundation received an NIH facilities award of $\$ 298,000$ that was matched by local gifts for construction of a new laboratory building. On April 12, 1958, the move to the new building (Fig. 2) was completed.

The additional space provided what were

Address correspondence and reprint requests to: Dr. Allen D. Cooper, Palo Alto Medical Foundation, Research Institute, 860 Bryant Street, Palo Alto, CA 94301. Phone: 415-3268120; Fax: 415-329-9114; e-mail: adc@leland.stanford.edu then modern laboratories, larger animal quarters, and ancillary facilities. Two new investigators with interests in immunology and infectious disease, and in bioengineering and physiology, were recruited. In addition, Barend Hofstee's work became widely recognized, and he is still remembered for the "Hofstee Plot" for expressing enzyme activity. Jack S. Remington, M.D., gained recognition for work on host resistance against opportunistic pathogens and Toxoplasma gondii; his group expanded to study Chagas' disease as well. Neil Ingels, Ph.D., and associates established new methods of studying cardiac dynamics. A new program in health economics was begun by Anne Scitovsky, who soon gained national recognition for her insightful work.

This is where matters stood as the beginnings of an endowment and greater stability developed. Slowly the emphasis of work moved in the direction of molecular biology. For shortly after arriving in the new laboratory in 1958, Barend Hofstee said, "If you don't know how it works, how can you fix it? That is the reason for basic research." This approach became central to the Research Foundation's function.

At the end of 1980, Palo Alto Medical Research Foundation merged with the Palo Alto Medical Clinic to become the Palo Alto Medical Foundation for Health, Research and Education. Research has continued in the now semiautonomous Research Institute. Upon Dr. Krupp's retirement in 1986, Dr. Allen Cooper assumed the directorship and moved his laboratory from Stanford University to the Research Institute.

The Research Institute is now comprised of three departments. Studies in the Department of Immunology and Cell Biology, chaired by Dr. Jack Remington, are directed at understanding host resistance to infection and the immunopathogenesis of the biology of Toxoplasma gondii and toxoplasmosis. Active projects are directed by Dr. Steve Parmley, who is investigating the mechanism of stage-specific gene expression by the parasite. Dr. Yasu Suzuki is studying the 


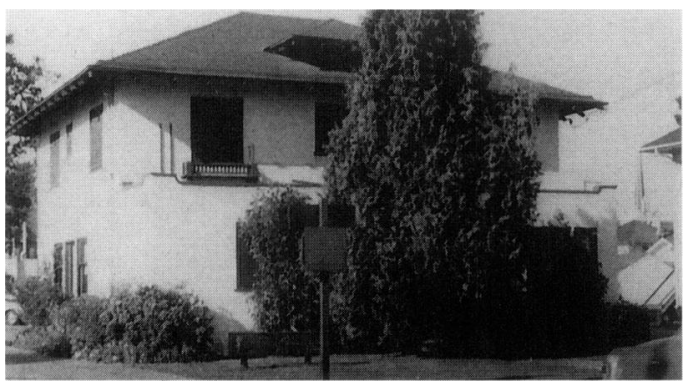

FIG. 1. The original headquarters of the Palo Alto Medical Foundation (1950-1957).

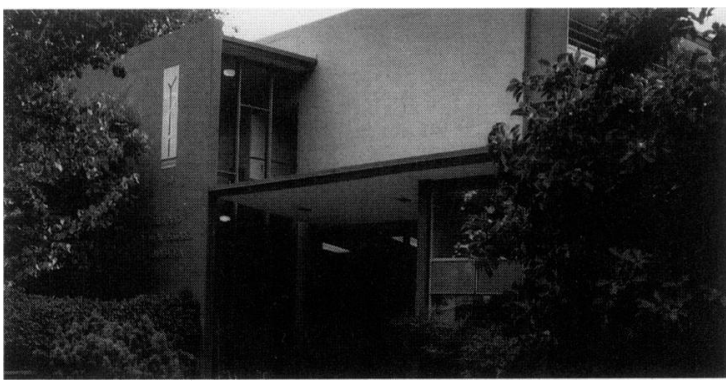

FIG. 2. The Medical Foundation occupied this newer building from 1958 to the present.

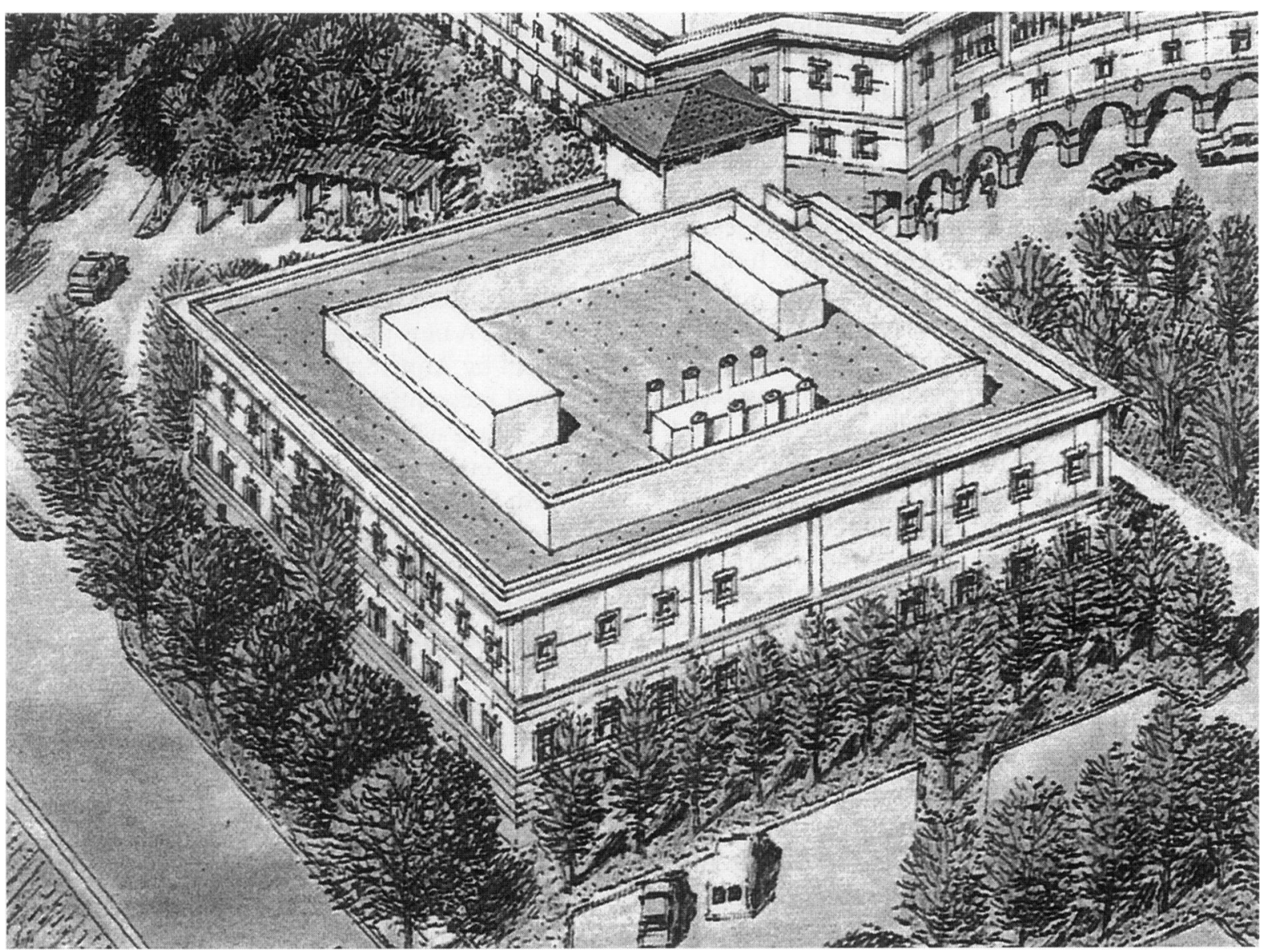

FIG. 3. The newest location, now under construction, is expected to be ready for occupancy in late 1998.

mechanisms of differences in genetic susceptibility to infection by toxoplasma in different mouse strains, with particular reference to understanding the genetic basis for differential expression of cellular immunity and cytokines. Dr. Fausto Araujo is involved in both the development and testing of drugs for treatment of toxoplasmosis, with particular reference to toxoplasmic enceph- alitis, a disease that has become common in patients with AIDS. Dr. Araujo is also studying the pathogenesis of the infection with Trypanosoma cruzi, a parasite commonly found in humans in Central and South America and occasionally in animals in the U.S. In addition to continuing his basic studies of the immune responses to $T$. gondii, Dr. Remington is conducting research aimed at 
early, rapid, and accurate diagnosis of toxoplasma, and he directs a clinical laboratory dedicated to this end that serves as a world-wide reference resource.

The Health Services Research Department (formerly Health Economics Department) is currently recruiting a new director as Anne Scitovsky is retiring from this post. She is widely recognized for having developed a methodology for estimating the costs of treatment of specific diseases. Medicare adopted this cost-of-illness approach when it began to pay hospitals according to a system of Diagnosis-Related Groups (DRGs), i.e., according to the cost of treatment of specific groups of illnesses. During the last decade, she applied her methodology to the costs of the AIDS epidemic; her first study in particular on the cost of AIDS in its early stage has had an important impact on public policy. Recently, she has completed a series of articles on medical care costs in the last year of a patient's life. Her most recent publication on this topic is "The High Cost of Dying Revisited."

The Department of Cardiovascular biology covers a breadth of interests. Dr. Neil Ingels and his colleague George Daughters are continuing long-time studies on the mechanisms of cardiac function. Their studies of torsional deformation have been extended to studies of mitral valve function. A new colleague, Dr. Srdjan Nikolic, is using new, three-dimensional, digital ultrasound technology to further our understanding of diastolic heart function, as well as valvular and vessel wall function.
Dr. Allen Cooper's major interest is in the metabolism of lipoproteins that carry dietary lipids, the chylomicron remnants. The mechanisms that control their removal by the liver and consequences of their prolonged residence in the circulation are being studied. He and his colleague Dr. Loren Fong, an expert in macrophage biology, are studying the mechanisms whereby these particles can lead to foam cell formation by macrophages, as well as activate endothelial cells. Dr. Sungshin Choi, the newest group member, is studying the mechanism of the participation of lipolytic enzymes in several of these processes. Dr. Beatriz Levy-Wilson, a senior molecular biologist, directs a program focused on understanding the molecular mechanisms that operate to control transcription of mammalian genes and the role that chromatin structure plays in these processes. Her studies utilize the genes encoding apolipoprotein B and cholesterol $7 \alpha$ hydroxylase as models of tissue-specific genes involved in the control of hepatic lipid metabolism.

The Research Institute has begun the construction of a new 40,000 sq. ft. facility that is scheduled for completion in late 1998 (Fig. 3), and will allow both modernization and expansion of the existing programs. The Institute's endowment also continues to grow, allowing it to sustain the vision of Dr. Krupp, which is that the Institute should be a venue where talented investigators are free to pursue their ideas in a relatively tranquil environment. 